\title{
Interfacial bonding of Flax fibre/Poly(I-lactide) bio-composites
}

\author{
Antoine Le Duigou ${ }^{\mathrm{a},{ }^{*}}$, Peter Davies ${ }^{\mathrm{b},{ }^{*}}$ and Christophe Baley ${ }^{\mathrm{a},{ }^{*}}$ \\ a LIMATB (Laboratoire d'Ingénierie des Matériaux de Bretagne), Université de Bretagne Sud - F - 56321 Lorient \\ CEDEX, France \\ ${ }^{\mathrm{b}}$ IFREMER, Materials and Structures Group, - F - 29280 Plouzané CEDEX, France \\ *: Corresponding author: P. Davies, Tel.: +33 29822 4777; fax: +33 29822 4535, email address : \\ Peter.Davies@ifremer.fr, A. Le Duigou, email address : antoine.le-duigou@univ-ubs.fr, C. Baley, email address : \\ christophe.baley@univ-ubs.fr
}

\begin{abstract}
:
The use of glass fibre reinforced polyester composites raises many health and safety and environmental questions. One alternative is the development of high performance bio-based biocomposites with low environmental impact. Improved understanding of interfacial properties is essential to optimise the mechanical properties and durability of these materials, but so far few data are available. The present work describes the interfacial characterization of Flax fibre/Poly(lactic) acid (PLLA) system at the micro-scale using the microbond test. Different thermal treatments have been carried out (cooling rate and annealing) in order to evaluate the influence of matrix and interfacial morphologies as well as residual stress on interfacial properties. Micromechanical models have been used to determine the interfacial shear strength. When cooling rate is slow, improved interfacial properties are observed.
\end{abstract}

Keywords: A. Flax fibre; A. Biopolymer; A. Biocomposite; B. Interfacial properties; D. Microbond test 


\section{Introduction}

Composite materials based on polyester resins reinforced with glass fibres are widely used in industrial applications. However, their use is raising some questions. First, polyester is obtained from non-renewable resources (oil), while the production of fibres requires a large amount of energy [1]. In addition volatile organic compounds (VOC's) are produced during the manufacture of composite parts. Finally, there is currently no end-of-life solution for these components which is economical and does not result in pollution. One possible solution is the development of bio-composites. These are composites manufactured using matrix and reinforcement both from renewable resources. There is currently extensive research in this area on account of their promising mechanical properties [2, 3], their recyclability after service [3] and their biodegradability [4]. The use of vegetable fibres also enables energy benefits to be achieved and greenhouse gas emissions to be limited, as photosynthesis is used for fibre production [5].

Le Duigou et al. [6] studied the influence of seawater aging on biocomposite properties, and showed that in flax/PLLA biocomposites damage at the fibre/matrix interface region was one of the main degradation mechanisms. This region is critical both for short term properties and long term durability. The strength of the interfacial bond depends on many parameters, including the surface energy, chemistry and roughness of the fibre. These parameters can be modified by different treatments [7-9]. The fibre-matrix bond can also be modified by addition of coupling agents $[8,10]$. Other work has shown that the curing temperature of thermoset matrix polymers can influence fibre-matrix interface properties [11]. For thermoplastic matrix polymers the thermal cycle (cooling rate, annealing...) can strongly influence interfacial behaviour. In some cases a particular oriented morphology has been observed at the fibre surface, oriented perpendicular to the fibre and known as a trans-crystalline region [12]. This zone may improve load transfer between fibres and matrix [13].

The characterization of an interfacial region is complex and can be performed at different scales:

Nanoscopic, with tests which measure microstrains and stresses within the fibres (Raman microscopy [14] ) or which measure adhesion forces between fibre and matrix (Colloïdal Probe Microscopy [15])

Microscopic, different tests have been used: fragmentation, pull-out, microbond, microindentation. These have been developed for the evaluation of adherence between fibre surfaces and the matrix. Their advantages and disadvantages discussed elsewhere [16]. One of the best-known is the microbond test, which consists of shearing a microdroplet of polymer off a single fibre (Fig. 3) [11, 17].

Macroscopic, using standard mechanical tests which favour off-axis loading.

The aim of the present work is to compare interfacial properties of Flax/Poly(L-Lactide) biocomposites with those of glass/polyester composites and others systems using a microbond test, micromechanical analysis and contact angle measurements. Cooling and annealing will be applied to examine the role of thermal stresses and polymer morphology on the interfacial properties. Evaluation of matrix mechanical and thermal properties as well as matrix morphology studies have been performed.

\section{Materials and methods}

The biopolymer (thermoplastic) studied here is a PLLA Poly(L-Lactic acid), the L9000 grade from Biomer ${ }^{\circledR}$. The thermosets resins are an isophthalic polyester (Norsodyne S 70361 TA with 1.5 wt\% MEKP catalyst), and a DGEBA epoxy (Axson Epolam 2015, with 32\% by weight aliphatic amine hardener). Polyester and epoxy resins were post cured at $65^{\circ} \mathrm{C}$ for $14 \mathrm{~h}$ after polymerization at room temperature. Flax fibres, of the Hermès type grown in Normandy, 
were dew-retted before being stripped and combed. E-glass fibre from Chomarat S.A. was used for comparison.

\subsection{Microdroplet manufacturing}

The first step in order to obtain single fibres is flax bundles separation. This is performed under an optical microscope, using tweezers to extract a fibre. A fibre specimen is then bonded to a thin paper frame which has a central longitudinal slot of fixed gage length. Each specimen is then re-examined under a microscope to check the fibre diameter.

Microdroplets are manufactured by tying a knot of PLLA around a single flax fibre. These are then placed in an oven. A suitable thermal treatment (Fig. 1) is needed to obtain a symmetrical (3 axis) droplet (Fig.2.). Microbond specimens are finally checked under the microscope to control the droplet geometry, length and height. Samples with defects (kink bands on the fibre or lack of symmetry of the droplet) are systematically removed. Besides being symmetrical, microdroplets need to be smaller than $250 \mu \mathrm{m}$ [18]. When the droplets are cooled at $1{ }^{\circ} \mathrm{C}$ /minute their length must not exceed $100 \mu \mathrm{m}$ in order to achieve debonding. This may be due to the loss in mechanical properties of longer fibres $[19,20]$ or to the improvement of interface properties. The variability of fibre cross-section must be considered when working at the micro-mechanics scale on natural fibres. A previous study has identified this parameter and showed that there is variation of fibre cross section according to the location within the plant and that diameter also varies along the fibre length, due to their inner structure [21]. We assume that drop length is small enough to be able to neglect fibre diameter variation along the droplet.

\subsection{Microbond test}

The microbond test has the advantage of a controlled embedded length, and contact angle measurement can also be made on this geometry. However, the properties of flax fibres (scatter in mechanical characteristics, discontinuous fibres, and variable section) can influence the micro-tension test results [7]. A tensile machine with a $2 \mathrm{~N}$ sensor is used with tensile speed of $0.1 \mathrm{~mm} / \mathrm{min}$. During the test the force and the crosshead displacement are measured as shown in Fig.3, a typical curve is shown in Fig. 4. Linear behaviour corresponding to elastic energy storage is observed until the force reaches the maximum value $\left(F_{\max }\right)$. Once $F_{\max }$ is reached debonding appears. The energy previously stored is released through fast interfacial cracking with a nearly constant friction force. From this moment only friction interactions occur [22]. In the present study it was not possible to differentiate the crack appearance from the debonding process because of the stiff and brittle behaviour of PLLA (Fig .5). The mechanical behaviour of PLLA is similar to that of standard polyester and epoxy resins.

\subsection{Micro-mechanical analysis}

The analysis of the results is based on micro-mechanics equations. The best known, developed by [23], is based on a value of $T_{\text {app }}$ using the assumption of a uniform distribution of interfacial stress, equation (1) :

$$
\tau_{\text {app }}=\frac{F_{\max }}{\pi D_{f} L_{e}}
$$

Where $F_{\max }$ is the maximum force recorded, $D_{f}$ is the diameter of the fibre, $L_{e}$ the droplet length.. We assume a circular fibre cross section, this is not strictly true but previous studies have shown that it is a close approximation (Fig.6). 
The apparent shear strength is determined from a linear regression of the plot of debonding force versus bonded area. A second value, the ultimate shear stress $\tau_{\text {utt }}$ [24], accounts for the non-uniformity of the stress state along the interface due to the end conditions and the loading. This value corresponds to the maximum value at the droplet ends near the knife edges. The residual thermal stresses $\tau_{t}$ are also included (2).

$$
\tau_{u l t}=\left[\frac{\tau_{a p p} L_{e} \beta}{\tanh \left(\beta L_{e}\right)}-\tau_{t} \tanh \left(\frac{\beta L e}{2}\right)\right]
$$

with $\quad \tau_{t}=\left[E_{f L} \frac{D_{f}}{4} \beta\left(\alpha_{f L}-\alpha_{m}\right) \Delta T\right]$

where $E_{f L}$ and $D_{f}$ are the longitudinal Young's modulus and the diameter of the fibres. $\alpha_{f L}$ and $\alpha_{m}$ are the thermal expansion coefficients of the fibre and the matrix (PLLA $\alpha_{m}=78.510^{-6}$ $I^{\circ} \mathrm{C}$ (for $\mathrm{T}<\mathrm{T}_{\mathrm{g}}$ ) ; Polyester $\alpha_{\mathrm{m}}=7510^{-6} /{ }^{\circ} \mathrm{C}$; Epoxy $\alpha_{\mathrm{m}}=78.510^{-6} /{ }^{\circ} \mathrm{C}$; flax fibre $\alpha_{\mathrm{fL}}=-1.10^{-6}$ $l^{\circ} \mathrm{C}$ [25] and glass fibre $\alpha_{\mathrm{fL}}=5.10^{-6} /{ }^{\circ} \mathrm{C}$ ). $\Delta \mathrm{T}$ is a parameter which must be included in the analysis as it determines the size of the residual stresses in both thermoplastic and thermosetting matrix polymers [26]. It corresponds to the difference between the stress free temperature (crystallization temperature for semi-crystalline polymers [27] or the $T_{g}$ for amorphous polymers) and the test temperature. The parameter $\beta$ is from shear-lag theory [24] :

$$
\beta^{2}=\frac{8 G_{m}}{E_{f L} D^{2} f \ln \left(\frac{D_{g}}{D_{f}}\right)}
$$

with $G_{m}$ the matrix shear modulus and $D_{g}$ the droplet diameter. More details are given by Zhandarov et al. [24]. An alternative approach, including thermal stresses, has been developed by Nairn et al. [28]. They described the quality of the fibre/matrix interface using a fracture mechanics analysis. The strain energy release rate is $G_{1}$ assuming that failure occurs when $G_{\mid}$reaches a critical value $G_{\mid c}$ (the fracture toughness). Equation 5, again based on Shear-Lag theory, provides this value and is valid for droplets with an aspect ratio (L/d) less than 5:

$$
\mathrm{G}_{\mathrm{ic}}=\frac{D_{f}}{4}\left[C_{33 s} \tau_{\mathrm{app}}^{2}+2 \tau_{\mathrm{app}} D_{3 S} \Delta T+\frac{\left(D_{3 S} \Delta T\right)^{2}}{C_{33 S}}\right]
$$

With $\quad C_{33 s}=\frac{1}{2}\left(\frac{1}{E_{f L}}+\frac{v f_{L T}}{v_{m} E_{m}}\right)$

and $\quad D_{3 s}=\frac{1}{2}\left(\alpha_{f L}-\alpha_{m}\right)$

where $v_{f_{L T}}$ and $v_{m}$ are respectively the Poisson's coefficient of the fibre and the matrix. $v_{f_{L T}}$ values are taken from [29].

Interfacial residual stresses or interfacial pressure can be evaluated by means of micromechanical models (8) [30],

$$
\sigma_{r r}\left(r_{f}, z\right)=\frac{\left(1+v_{t_{L}}\right)\left(\alpha_{m}-\alpha_{f L}\right) \Delta T}{\left(\frac{1-v_{t f}}{E_{f T}}+\frac{\left(1+v_{m}\right)}{E_{m}}-\frac{2 v_{l f}^{2}}{E_{f T}}\right)}
$$


where $\sigma_{\mathrm{rr}}$ is the radial stress, $v$ is the Poisson's coefficient, $E$ is the Young's modulus with $f$ for fibre, $\mathrm{m}$ for matrix, $\mathrm{L}$ for longitudinal and $\mathrm{T}$ for transverse. $\Delta \mathrm{T}$ is the temperature range as defined earlier.

\subsection{Contact angle measurement}

Before debonding, the contact angles between the flax fibre and the solid matrix with the microdroplet are measured by image analysis. The determination of contact angle was achieved using the Length-Height method [31] for drop-on-fibre systems. This method increases accuracy and reliability by taking into account a large part of the drop profile in the calculation. At the same time the ratio (embedded length divided by the microdroplet diameter) is determined.

\subsection{Dynamic Scanning Calorimetry (DSC)}

DSC tests were carried out with Mettler Toledo apparatus. The first thermal scan was used because it includes the thermal history of the PLLA. Samples were heated to $190^{\circ} \mathrm{C}$ to determine crystallization and melting enthalpies. Degree of crystallinity was estimated using equation 9.

$$
\chi_{c}=\frac{\Delta H_{m}-\Delta H_{c}}{\Delta H_{10 \%}}
$$

with $\Delta \mathrm{H}_{\mathrm{c}}$ and $\Delta \mathrm{H}_{\mathrm{m}}$ the crystallization and melting enthalpies. $\Delta \mathrm{H}_{100 \% \text { crystalline }}=93.7 \mathrm{~J} / \mathrm{g}$ [32] is the theoretical melting enthalpy of $100 \%$ crystalline PLLA. Different cooling rates (corresponding to thermal treatments of microdroplets) have been applied to determine crystallization temperature $T_{c}$ and glass transition temperature $T_{g}$.

\subsection{Static tensile tests}

Dog-bone PLLA samples were manufactured by hot compression moulding in a normalized mould. Different cooling rates were achieved to correlate with microdroplet cooling kinetics and to determine the effect of cooling rate on the tensile and shear properties of the matrix. Tensile tests were carried out at $1 \mathrm{~mm} / \mathrm{min}$ following the ISO 527 standard. A biaxial extensometer was used to determine Young's modulus and Poisson's coefficient.

\subsection{Polarization microscopy}

PLLA is a semi-crystalline thermoplastic, during cooling crystallization phenomena occur. A specific matrix morphology, known as trans-crystallization, can also appear around the fibre. To study interfacial morphology, stacks of polymer film/fibre/polymer film (sandwich) were prepared by hot compression [33] and cooled at different rates, observing the micro-structure during cooling with a microscope equipped with hot plates.

\subsection{SEM examination}

The fracture surfaces were analyzed by scanning electron microscopy (SEM). The samples were sputter-coated with a thin layer of gold in an Edwards Sputter Coater, and observed with a Jeol JSM 6460LV scanning electron microscope. 


\section{Results \& discussion}

\subsection{Microbond test}

Table 1 presents interfacial properties such as the average shear stress $T_{a p p}$ and the microdroplet friction after debonding. The same device was used as in reference [11], previous results are also shown in Table 1. Analysis of the friction gives an indication of the thermal stress state in the sample. Moreover, different thermal treatments (cooling rate and annealing below the glass transition temperature) help to understand the role of thermal stress and matrix morphology in interfacial phenomena in the Flax/PLLA bond. An annealing treatment was performed below $\mathrm{T}_{\mathrm{g}}$ on quasi-amorphous samples (air cooled) in order to release residual stress without involving re-crystallization. Samples have been followed by DSC, and endothermic peaks were observed around $\mathrm{T}_{\mathrm{g}}$ (not shown here). First, the results indicate that Interfacial Shear Strength (IFSS) of flax/PLLA systems are in the same range as those of glass fibre/polyester, flax fibre/polyester and flax/epoxy. The adhesion between a flax fibre and PLLA is however lower than that of glass/epoxy samples, as expected given the many years of development of appropriate fibre sizings for the latter. The apparent interfacial shear strength of the flax/PLLA systems given in Table 1 is higher than those measured by Morlin et al [34] on similar combinations ( $\mathrm{T}$ app $=8.98 \pm 2.99 \mathrm{MPa}$ ) but they tested bundles of fibres, not single filaments. Cooling rate has an important influence on interfacial properties of Flax/PLLA. At slow cooling rate the average IFSS increases. Annealing PLLA below $T_{g}$ releases thermal stress and reduces interfacial properties of Flax fibre/PLLA (Table 1). Hence thermal residual stresses induced by rapid cooling rate have an influence on interfacial properties. Indeed, during rapid cooling the matrix structure, which shows visco-elastic behaviour, does not have time to relax [26]. Thus the residual stresses that appear during this phase will control interfacial properties. Analysis of friction shows an increase of friction stress at low cooling rate, confirming the increasing role of residual stress. Release of thermal stress during annealing reduces friction stresses (Table 1).

\subsection{SEM examination}

SEM photos (Fig. 7a and b) show that PLLA droplets (Fig. 7a) have different fracture initiation mechanisms compared to epoxy droplets (Fig. 7b). Fracture of flax/PLLA is interfacial (Fig 7a) which suggests physical interactions such as Van Der Waals interactions between fibre and polymer. Indeed, unlike thermoset resins for which interfacial bonding is mainly formed by chemical bonds, adherence between fibres and thermoplastic resins result from physical interactions influenced by compressive residual stresses [26, 35]. The Van der Waals bonds can result in high global energies but they show poor durability (low resistance to hydrolysis for example) [36]. For epoxy droplets the crack is initiated in mode I in the matrix and propagates into the interfacial area (Fig 7b).

\subsection{Micromechanical analysis}

The data recorded during debonding tests were analysed using the micromechanics equations (1, 2 and 5). The apparent interfacial strength $T_{a p p}(1)$, the ultimate strength $T_{\text {ult }}(2)$ and the critical strain energy release rate $G_{\mathrm{lc}}(5)$ were calculated. The residual stresses induced during cooling were evaluated via the $\sigma_{\mathrm{rr}}$ value (8). These results show a clear trend for the influence of cooling rate on the interfacial properties. Slow cooling $\left(1^{\circ} \mathrm{C} / \mathrm{min}\right)$ results in an increase in the shear resistance of the interfacial region, while the relaxation of residual stresses (annealing), confirmed by the reduction in $\sigma_{\mathrm{rr}}$, decreases the bond properties. The results also underline the similarity between shear strength values ( $T_{\text {app }}$ et $T_{\text {ult }}$ ) for flax/PLLA 
and flax/polyester, flax/epoxy and glass/polyester. The ultimate strength values are significantly higher than the apparent shear strengths. The former, $\mathrm{T}_{\mathrm{ult}}$, is a local stress corresponding to the edge of the knife loading zone and the point at which the fibre enters the droplet. $\mathrm{T}_{\text {ult }}$ represents a limit to $\mathrm{T}_{\mathrm{app}}$ when the debonded droplet length tends to 0 [37]. It includes the development of residual thermal stresses ( $\alpha$ and $\Delta \mathrm{T}$ ). Analysis of radial stress $\sigma_{\mathrm{rr}}$ (or interfacial pressure) shows an increase at low cooling rate, confirming the increasing role of residual stress. The interfacial pressure or radial stress originates from the matrix shrinkage and the resulting residual stress generated during cooling [11]. Release of thermal stress during annealing reduces radial stress (Table 2). This follows the same trend as that observed for IFSS (Table 2.). Radial stresses in flax/PLLA systems are higher than in glass/Polyester and flax/epoxy systems and are in the same range as those measured on glass/epoxy and flax/Polyester. Some care is needed in interpreting the results from this type of micromechanical approach (average shear Strength and Friction models). First, the average shear strength model is simple but this approach assumes a constant stress distribution along the interface; some authors $[16,38]$ have demonstrated that this is not the case. In addition this model does not take into account thermal stresses and produces scattered results. The use of an ultimate interfacial strength, $\mathrm{T}_{\text {ult }}$, on the other hand, based on shear lag theory, includes the response of local phenomena. There is some discussion over whether energy based models are better suited to analyze this type of test, [17]. Van de Weyenberg et al. [39] suggest that stress based models are better for initiation and short debond lengths, while energy models are preferable when $L / d>20$ and to describe propagation. Determination of $G_{\mid c}$ requires the free fibre length (between the machine grips and the droplet) to be short, to minimize elastic strain energy. All the micromechanical models take into account the value of the thermal expansion coefficient of PLLA. However it is only determined over a small temperature range $\left(-20\right.$ to $\left.60^{\circ} \mathrm{C} T<T_{g}\right)$ which may underestimate the true value of $\alpha$. Indeed determination of thermal expansion coefficients should involve all variation of free volume over the whole temperature range of microdroplet manufacturing. However, these coefficients are not constant over this temperature range, so this is a source of error in the analysis. $\Delta T$ depends on the viscoelastic behaviour of the polymer and this should ideally be included in the analysis [40]. For a semi-crystalline polymer the degree of crystallinity and the crystallization kinetics will also play a role in the development of residual stresses [41]. Other factors which will affect the analysis are the idealized shape used in the calculation of the droplet volume, spherical, elliptic [17] or cylindrical [18], and the influence of the true fibre section. The polygonal shape of flax fibres (Figure 6) may also modify the stress distribution along the interface. It is clear that micromechanical models for this type of system should be used with caution. Nethertheless, microbond testing provides interesting comparative data that make it possible to interpret interfacial phenomena.

\subsection{Study of contact angle and aspect ratio of microdroplets}

Contact angles between flax fibres and PLLA matrix, as well as aspect ratios (embedded length/diameter), have been measured before debonding, The results in Table 3 show that the contact angle tends to decrease at slower cooling rate (from $42.5^{\circ} \pm 9^{\circ}$ for air cooling to $33.5^{\circ} \pm 8.1^{\circ}$ at $1^{\circ} \mathrm{C} / \mathrm{min}$ cooling rate). Published numerical studies and photo-elasticity measurements $[16,42]$ have shown that the droplet geometry, and hence the contact angle, influence the shear stress state at the end of the droplet, by changing the contact point with the knife edge and hence modifying damage mechanisms. Moreover, contact angles for PLLA droplets, for each thermal treatment, are larger (around double) compared to those of thermoset matrix with glass and flax fibres. These differences may not be explained by differences in surface tension (for PLLA $\gamma_{s}=40.1 \pm 1.1 \mathrm{~mJ} / \mathrm{m}^{2}$ [10]; polyester $\gamma_{s}=44.2 \pm 1$ $\mathrm{mJ} / \mathrm{m}^{2}$ [11] and for epoxy $\gamma_{\mathrm{s}}=40.8 \pm 2.3 \mathrm{~mJ} / \mathrm{m}^{2}$ [11]) but by several others parameters such as the difference in shrinkage, the magnitude of residual stress inside the droplet, the difference in viscosity and the temperature of polymer deposit which may involve modification of the flax 
fibre surface. The aspect ratio (embedded length/diameter) shows good reproducibility between samples, and increases with low cooling rate which correlates with the trend followed by contact angles.

\subsection{Thermo-mechanical analysis of PLLA}

Table 4 shows thermal properties of PLLA samples obtained with the same thermal treatment as the microdroplet. The values of crystallization and melting enthalpies were taken from the first DSC scans. The stress free temperature and $\Delta T$ were determined at a suitable cooling rate using DSC. Determination of $\Delta T$ values is important to evaluate thermal stresses induced by the cooling process [26]. When crystallization occurs during cooling, the stress free temperature is equal to crystallization temperature [27]. For slow and intermediate cooling, the crystallization temperature of PLLA is taken as the stress free temperature while for the air cooled sample $T_{g}$ is taken because no crystallization peak appears during cooling. $\Delta T$ values are higher with slower cooling rate.

Cooling rates modify the crystalline structure of the PLLA matrix, and the degree of crystallinity increases when cooling rate is slow (Table 4). A high degree of crystallinity induces higher shrinkage of the matrix and thus increases the difference between thermal expansion coefficients of the matrix and the fibre. Parlevliet et al. [26] claim that this difference generates residual compressive stresses which are involved in the stress transfer mechanism between matrix and fibre. Our results calculated by Eq. 8 confirm this. Moreover $\Delta T$ ( $\left.T_{\text {free }}-T_{\text {test }}\right)$ values increase with decreasing cooling rate. The magnitude of thermal residual stress is also influenced by $\Delta T$. As cooling rate influences the temperature at which thermal stress are frozen [26] the slower the cooling rate the more $T_{\text {free }}$ increases (Table 4) and as a consequence $\Delta T$ and thermal stress also increase. The difference in thermal coefficients and $\Delta T$ are taken into account in the micromechanical equations used to evaluate residual stress in Table 1.The annealing treatment below $T_{g}$ does not induce crystallization. Change of PLLA structure involves modification of mechanical properties such as tensile and shear properties (Table 5). As it is difficult to evaluate mechanical properties directly on microdroplets, tensile test samples of PLLA were manufactured with controlled cooling rate. For technical reasons it was not possible to achieve exactly the same cooling rate (Table 5). Moreover air cooled droplets have a cooling rate which is not easy to quantify, but must be very quick given the small size of the specimen. The water cooling rate $\left(93^{\circ} \mathrm{C} / \mathrm{min}\right)$ measured on tensile specimens is estimated to be a reasonable approximation for air cooling of a microdroplet. Indeed thermal analyses (not presented) have demonstrated similar trends with close values of crystallization and melting enthalpies to those of microdroplet samples. Shear properties $(G, \tau)$ can be estimated from tensile properties by assuming an isotropic nature of the matrix (10 and 11$)$ :

$$
G_{m}=\frac{E_{m}}{2\left(1+v_{m}\right)}
$$

with $G_{m}$ shear modulus of the matrix, $E_{m}$ tensile modulus and $v_{m}$ Poisson's coefficient

$$
\tau_{m}=\frac{\sigma_{m}}{\sqrt{3}}
$$

with $\mathrm{T}_{\mathrm{m}}$ the shear strength of the matrix, $\sigma_{\mathrm{m}}$ the tensile strength.

Thermal expansion coefficient was determined by DMA (compression mode) over a temperature range from -20 to $60^{\circ} \mathrm{C}$. Mechanical properties of the PLLA matrix change with cooling rate. At the slowest cooling rate $\left(1.5^{\circ} \mathrm{C} / \mathrm{min}\right)$, a high degree of crystallinity of the PLLA improves tensile and shear properties. Increasing tensile modulus will influence the formation 
of residual stress [26] . Furthermore, an increase in Poisson's coefficient is noted when cooling rate is slow. Thermal expansion coefficient does not vary with cooling rate over the small temperature range examined. This range does not include a large variation of free volume compared to temperatures around the crystallization temperature [26]. Further analysis over a wider range would show a variation of thermal expansion coefficient with degree of crystallinity.

\subsection{Analysis of matrix and interfacial morphology}

Polarization microscopy makes it possible to observe the polymer structure and to correlate this with DSC measurements. Figure $8 \mathrm{a}, 9 \mathrm{a}$ and $10 \mathrm{a}$ show results from PLLA/Flax/PLLA sandwich observations for different cooling rates, and a correlation with microdroplet samples. Air cooled samples (Fig.8a) exhibit quasi-amorphous structure, with very small and rare spherulites. Intermediate cooling at $10^{\circ} \mathrm{C} / \mathrm{min}$ (Fig 9a) results in a few more spherulites with larger size. Slow cooled samples $\left(1^{\circ} \mathrm{C} / \mathrm{min}\right)$ (Fig. 10a) have a crystalline structure with large spherulites.

In addition to matrix modification, cooling rate also influences fibre/matrix interfacial area morphology. Besides a higher number of spherulites with slow cooling kinetics, one can notice a growing trans-crystallization region around the flax fibre (Fig 9a and 10a). The formation mechanism of this region and its effect on mechanical properties are still not clear, and depend on the fibre/matrix studied [12] but the results from the present study are in agreement with those of $[43,44]$. According to $[13,26,41]$ the anisotropy of the transcrystalline zone increases both thermal stress and mechanical anchorage between fibre and matrix [26, 30,35]. Mechanical interlocking is also favoured by the rough, porous surfaces of natural fibres [36].

\section{Conclusion}

This paper presents results from a study on interfacial properties of a Flax fibre/PLLA system which is compared to other systems including Flax/Polyester, Flax/Epoxy, Glass/Polyester and Glass/Epoxy.

Microbond tests allow the Interfacial Shear Strength (IFSS) and friction stress of Flax fibre/PLLA bonds to be estimated. Interfacial properties of Flax/PLLA bonding are in the same range as those measured on Glass/Polyester. To improve understanding of the phenomena which govern the interfacial mechanisms in Flax/PLLA biocomposite different thermal treatments (different cooling rates and annealing to release thermal stress) have been carried out, resulting in different micro-structures and residual stress states inside the material. Cooling kinetics have been shown to modify interfacial properties ( $T_{a p p}, T_{u l t}, G_{i c}$, $T_{\text {friction }}$ and $\sigma_{\text {rr }}$.). Indeed when cooling rate is slow, the interfacial properties improve, and a high degree of crystallinity is measured with transcrystallinity around the flax fibre (Fig 9a and 10a). The more crystalline morphology of the matrix results in improvement of mechanical properties (tensile and shear) and higher residual compressive stress (Table 1). Interfacial properties are hence controlled by two competing mechanisms : Thermal residual stress induced by crystallization and trans-crystallization phenomena. Additional parameters are $\Delta T$ (the difference between stress free temperature and test temperature) for slow cooling rates, and the matrix relaxation governed by visco-elastic behaviour of the matrix at rapid cooling rates. Evaluation of interfacial properties using micro-mechanics models has enabled the influence of processing on properties to be evaluated, though the limits of these models with respect to the true geometry and test conditions must also be considered. Contact angle measurements are also influenced by the cooling kinetics and polymer morphology (Table 3). Current studies are focussing on the translation of these effects at the microscopic level to global composite mechanical properties. 


\section{References}

1. Corbière-Nicollier $T$, Gfeller Laban $B$, Lundquist $L$, Leterrier $Y$, Månson J-AE, and Jolliet $\mathrm{O}$, Life cycle assessment of biofibres replacing glass fibres as reinforcement in plastics. Res, Cons Recyc, 2001. 33(4): p. 267-287.

2. Bodros E, Pillin I, Montrelay N, and Baley C, Could biopolymers reinforced by randomly scattered flax fibre be used in structural applications ? Comp Sci \&Technol, 2007. 67(3-4): p. 462-470.

3. Le Duigou A, Pillin I, Bourmaud A, Davies P, and Baley C, Effect of recycling on mechanical behaviour of biocompostable flax/poly(l-lactide) composites. Comp. Part A, 2008. 39(9): p. 1471-1478.

4. Baley C, Grohens Y, and Pillin I, Etat de l'art sur les matériaux composites biodégradables. RCMA, 2004. 14: p. 135-166.

5. Bewa $\mathrm{H}$, Renforcement des polymères par des fibres végétales. Revue des matériaux composites. Vol. 16. 2006: Hermès-Lavoisier.

6. Le Duigou A, Davies P, and Baley C, Seawater ageing of Flax/PLLA biocomposites. Polymer Degradation and Stability, 2009. 94(1151-62).

7. Baley C, Busnel F, Grohens Y, and Sire O, Influence of chemical treatments on surface properties and adhesion of flax fibre-polyester resin. Composite Part A: Applied Science and Manufacturing, 2006. 37(10): p. 1626-1637.

8. Arbelaiz A, Cantero G, Fernández B, Mondragon I, Gañán P, and Kenny J, Flax fiber surface modifications: Effects on fiber physico mechanical and flax/polypropylene interface properties. Polymer Composites, 2005. 26(3): p. 324-332.

9. Stamboulis A, Baillie C, and Schulz E, Interfacial characterisation of flax fibrethermoplastic polymer composites by the pull-out test. Die Angewandte Makromolekulare Chemie, 1999. 272(1): p. 117-120.

10. Bourmaud A, Riviere J, Le Duigou A, Raj G, and Baley C, Investigations of the use of a mussel-inspired compatibilizer to improve the matrix-fiber adhesion of a biocomposite. Polymer Testing, 2009(1-5).

11. Baley C, Grohens Y, Busnel F, and Davies P, Application of interlaminar test to marine composites. Relation between glass fibre/polymer interfcaes and interlaminar properties of marine composites. Applied Composite Materials, 2004. 11: p. 77-98.

12. Quan H, Li Z, Yang M, and Huang R, On transcrystallinity in semi-crystalline polymer composites. Composites Science and Technology, 2005. 65(7-8): p. 999-1021.

13. Unger WJ and Hansen JS, The effect of cooling rate and annealing on residual stress development in graphite fibre reinforced PEEK laminates. Composites Material, 1993. 29: p. 108-137.

14. Eichhorn $S$ and Young $R$, Deformation micromechanics of natural cellulose fibre networks and composites. Composites Science and Technology, 2003. 63(9): p. 1225-1230.

15. Raj G, Balnois E, Baley C, and Grohens Y, Colloid Force measurements between Cellulose and Polylactic Acid (PLA). RCMA, 2008. 18(2): p. 177-83.

16. Herrera-Franco $P$ and Drzal $L$, Comparison of methods for the measurement of fibre/matrix adhesion in composites. Composites, 1992. 23(1).

17. Zinck P, Wagner HD, Salmon L, and Gerard JF, Are microcomposites realistic models of the fibre/matrix interface? I. Micromechanical modelling. Polymer, 2001. 42(12): p. 54015413.

18. Liu C and Nairn J, Analytical and experimental methods for a fracture mechanics interpretation of the microbond test including the effects of friction and thermal stresses. International Journal of Adhesion and Adhesives, 1999. 19(1): p. 59-70.

19. Gassan J and Bledzki A, Thermal degradation of flax and jute fibers jute. Journal of Applied Science, 2001. 82(6): p. 1417-22.

20. Baley C, Morvan C, and Grohens $\mathrm{Y}$, Influence of the absorbed water on the tensile strength of flax fibers, in Polymer-Solvent complexes and intercalates V, Y.Grohens, Editor. 2004, Wiley-VCH: Lorient. 
21. Charlet K, Baley C, Morvan C, Jernot JP, Gomina M, and Bréard J, Characteristics of Hermès flax fibres as a function of their location in the stem and properties of the derived unidirectional composites. Composite Part A: Applied Science Manufacturing, 2007. 38(8): p. 1912-1921.

22. Zhandarov $\mathrm{S}$ and Mäder $\mathrm{E}$, Characterization of fiber/matrix interface strength: applicability of different tests, approaches and parameters. Composites Sciences Technology, 2005. 65(1): p. 149-160.

23. Miller B, A microbond method for determination for determination of the shear strength of a fiber/resin interface. Composites Science and Technology, 1987. 28: p. 17-32.

24. Zhandarov S and Pisanova E, The local bond strength and its determination by fragmentation and pull-out tests. Composites Science and Technology, 1997. 57(8): p. 957964.

25. Pomel $\mathrm{C}$, Contribution à l'étude de matériaux composites renforcés par des fibres de lin, in mécanique, thermique et Génie civil. 2003, Université de Nantes: Nantes.

26. Parlevliet $P$, Bersee $H$, and Beukers $A$, Residual stresses in thermoplastic composites--A study of the literature--Part I: Formation of residual stresses. Composite Part A: Applied Science and Manufacturing, 2006. 37(11): p. 1847-1857.

27. Nairn JA and Zoller $\mathrm{P}$, Matrix solidification and the resulting residual thermal stresses in composites. Journal of Material Science, 1985. 20(1): p. 355-367.

28. Nairn J, On the use of shear-lag methods for analysis of stress transfer in unidirectional composites. Mechanics of Materials, 1997. 26(2): p. 63-80.

29. Baley C, Analysis of the flax fibres tensile behaviour and analysis of the tensile stiffness increase. Composite Part A: Applied Science and Manufacturing, 2002. 33(7): p. 939-948.

30. DiLandro $L$ and Pegoraro $M$, Evaluation of residual stresses and adhesion in polymer composites. Composites, 1996. 27A: p. 847-853.

31. Song B, Bismarck A, Tahhan R, and Springer J, A generalized drop length-height method for determination of contact angle in drop-on-fiber systems. Journal of colloid interface science, 1998. 197: p. 68-77.

32. Ray S, Yamada K, Okamoto M, and Ueda K, Crystallization behaviour and morphology of biodegradable polylactide/layered silicate nanocomposite. Polymer, 2003. 44: p. 857-866.

33. Cartledge $\mathrm{H}$ and Baillie $\mathrm{C}$, Studies of microstructural and mechanical properties of nylon/glass composite Part I The effect of thermal processing on crystallinity, transcrystallinity and crystal phases. Journal of Material Science, 1999. 34(20): p. 50995111.

34. Morlin B and Czigany $\mathrm{T}$, Investigation of the surface adhesion of natural fiber reinforced polymer composites with acoustic emission technique. Proceeding of the 8th Polymers for advanced Technologies International Symposium, 2005.

35. Parlevliet $P$, Bersee $H$, and Beukers $A$, Residual stresses in thermoplastic composites - a study of the literature. Part III: Effects of thermal residual stresses. Composite Part A: Applied Science and Manufacturing, 2007. 38(6): p. 1581-1596.

36. Nardin M, Interface fibre-matrice dans les matériaux composites- Application aux fibres végétales. Renforcement des polymèes par des fibres végétales- journée scientifique et technique- AMAC, ed. R.d.c.e.d.m. avancés. Vol. 16. 2006: Hermes-Lavoisier.

37. Pisanova $E$, Zhandarov $S$, and Mäder $E$, How can adhesion be determined from micromechanical tests? Composite Part A: Applied Science and Manufacturing, 2001. 32(34): p. 425-434.

38. Day RJ and Rodrigez JVC, Investigation of the micromechanics of the microbond test. Composites Science and Technology, 1998. 58(6): p. 907-914.

39. Van de Weyenberg I, Flax fibres as a reinforcement for epoxy composites. 2005, Katholieke Universiteit Leuven.

40. Di Landro $L$ and Pegoraro $M$, Evaluation of residual stresses and adhesion in polymer composites. Composite Part A: Applied Science and Manufacturing, 1996. 27(9): p. 847-853. 
41. Nielsen A and Pyrz R, The effect of cooling rate on thermal residual strains in carbon/polypropylene microcomposites. Sci Eng Compos Mater, 1998. 32(4): p. 1-22.

42. Ash JT, Cross WM, Svalstad D, Kellar JJ, and Kjerengtroen L, Finite element evaluation of the microbond test: meniscus effect, interphase region, and vise angle. Composites Science and Technology, 2003. 63(5): p. 641-651.

43. Felix $\mathrm{J}$ and Gatenholm $\mathrm{P}$, Effect of transcrystalline morphology on interfacial adhesion in cellulose/polypropylene composites. Journal of Material Science, 1994. 29(11): p. 30433049.

44. Zafeiropoulos NE, Baillie CA, and Matthews FL, A study of transcrystallinity and its effect on the interface in flax fibre reinforced composite materials. Composite Part A: Applied Science and Manufacturing, 2001. 32(3-4): p. 525-543.

\section{Acknowledgments}

The authors wish to thank Brittany region for financial support and acknowledge the support of the Pôle Mer, CG56, Vannes agglomeration and the city of Lorient.

\section{Tables}

Table 1. Influence of thermal treatments on interfacial properties.

\begin{tabular}{|c|c|c|c|c|c|}
\hline Material & \multicolumn{2}{|c|}{ Thermal treatment } & $\begin{array}{c}\mathrm{T}_{\text {app }} \\
(\mathrm{MPa})\end{array}$ & $\begin{array}{l}\mathrm{T}_{\text {friction }} \\
(\mathrm{MPa})\end{array}$ & Ref. \\
\hline \multirow{4}{*}{ Flax/PLLA } & \multirow{3}{*}{ Cooling } & Air & $15.3 \pm 3.3$ & $7.7 \pm 1.5$ & \\
\hline & & $10^{\circ} \mathrm{C} / \mathrm{min}$ & $18.2 \pm 1.8$ & $8.2 \pm 1.9$ & \\
\hline & & $1^{\circ} \mathrm{C} / \mathrm{min}$ & $\begin{array}{c}22.2 \pm \\
3.4\end{array}$ & $8.8 \pm 3.3$ & \\
\hline & annealing & $\begin{array}{c}50^{\circ} \mathrm{C} \\
\text { during } 72 \mathrm{~h}\end{array}$ & $9.9 \pm 1.5$ & $6.4 \pm 2.4$ & \\
\hline Flax/Epoxy & \multirow{4}{*}{ curing } & \multirow{4}{*}{$\begin{array}{c}65^{\circ} \mathrm{C} \\
\text { during } 14 \mathrm{~h}\end{array}$} & $16.1 \pm 0.8$ & $\begin{array}{c}5.44 \pm \\
2.18\end{array}$ & \\
\hline Flax/Polyester & & & $14.2 \pm 0.4$ & $9.8 \pm 4.6$ & \\
\hline Glass/Epoxy & & & $29.3 \pm 2.4$ & $7.7 \pm 1.4$ & \multirow{2}{*}{ [11] } \\
\hline Glass/Polyester & & & $14.2 \pm 0.4$ & $4.4 \pm 0.7$ & \\
\hline
\end{tabular}




\begin{tabular}{|c|c|c|c|c|c|c|c|}
\hline Material & \multicolumn{2}{|c|}{ Thermal treatment } & $\begin{array}{c}\mathrm{T}_{\mathrm{app}} \\
\text { (MPa) } \\
(1)\end{array}$ & $\begin{array}{c}\mathrm{T}_{\text {ult }} \\
\text { (MPa) } \\
(2)\end{array}$ & $\begin{array}{c}\mathrm{G}_{\mathrm{IC}} \\
\left(\mathrm{J} / \mathrm{m}^{2}\right) \\
(5)\end{array}$ & $\begin{array}{c}\sigma_{\mathrm{rr}} \\
(\mathrm{MPa}) \\
(8)\end{array}$ & Ref. \\
\hline \multirow{4}{*}{ Flax/PLLA } & \multirow{3}{*}{ cooling } & Air & $\begin{array}{c}15.3 \pm \\
3.3\end{array}$ & $\begin{array}{c}65.0 \pm \\
23\end{array}$ & $\begin{array}{c}28.5 \pm \\
17\end{array}$ & 5.52 & \\
\hline & & $10^{\circ} \mathrm{C} / \mathrm{min}$ & $\begin{array}{c}18.2 \pm \\
1.8 \\
\end{array}$ & $\begin{array}{c}80.5 \pm \\
25.5\end{array}$ & $\begin{array}{c}32.6 \pm \\
14\end{array}$ & 14.67 & \\
\hline & & $1^{\circ} \mathrm{C} / \mathrm{min}$ & $\begin{array}{r}22.2 \\
\pm 3.4 \\
\end{array}$ & $\begin{array}{c}95.7 \pm \\
19 \\
\end{array}$ & $\begin{array}{c}41.4 \pm \\
16.8\end{array}$ & 18.3 & \\
\hline & annealing & $\begin{array}{c}50^{\circ} \mathrm{C} \\
\text { during } \\
72 \mathrm{~h}\end{array}$ & $\begin{array}{c}9.9 \pm \\
1.5\end{array}$ & $\begin{array}{c}40.6 \pm \\
13.1\end{array}$ & $\begin{array}{c}12.9 \pm \\
1.6\end{array}$ & 4.28 & \\
\hline Flax/Epoxy & \multirow{4}{*}{ curing } & \multirow{4}{*}{$\begin{array}{c}65^{\circ} \mathrm{C} \\
\text { during } \\
14 \mathrm{~h}\end{array}$} & $\begin{array}{c}16.1 \pm \\
0.8\end{array}$ & $\mathrm{x}$ & $\begin{array}{c}78.1 \pm \\
10.4\end{array}$ & 5.74 & \\
\hline Flax/Polyester & & & $\begin{array}{c}14.2 \pm \\
0.4\end{array}$ & $x$ & $\begin{array}{c}45.4 \pm \\
11.9\end{array}$ & 7.13 & \\
\hline Glass/Epoxy & & & $\begin{array}{c}29.3 \pm \\
2.4\end{array}$ & $\begin{array}{c}74.7 \pm \\
9.7\end{array}$ & $\begin{array}{c}62.2 \pm \\
12.3 \\
\end{array}$ & 8.8 & \multirow{2}{*}{ [11] } \\
\hline Glass/Polyester & & & $\begin{array}{c}14.2 \pm \\
0.4\end{array}$ & $\begin{array}{c}70.9 \\
\pm 14.7\end{array}$ & $\begin{array}{c}41.1 \pm \\
6.5\end{array}$ & 10.6 & \\
\hline
\end{tabular}

Table 2. Micromechanical analysis of the influence of thermal treatments on interfacial properties

Table. 3 Contact angle between flax fibres, glass fibres and resin (PLLA, Polyester and Epoxy) and aspect ratio of microdroplet (embedded length/diameter)

\begin{tabular}{|c|c|c|c|c|c|}
\hline Material & \multicolumn{2}{|c|}{ Thermal treatment } & $\theta\left({ }^{\circ}\right)$ & $\mathrm{L}_{\mathrm{e}} / \mathrm{D}_{\mathrm{g}}$ & Ref. \\
\hline \multirow{4}{*}{ Flax/PLLA } & \multirow{3}{*}{ Cooling } & Air & $42.5 \pm 9$ & $1.3 \pm 0.1$ & \\
\hline & & $10^{\circ} \mathrm{C} / \mathrm{min}$ & $35.2 \pm 10$ & $1.34 \pm 0.16$ & \\
\hline & & $1^{\circ} \mathrm{C} / \mathrm{min}$ & $33.5 \pm 8.1$ & $1.49 \pm 0.9$ & \\
\hline & annealing & $\begin{array}{c}50^{\circ} \mathrm{C} \\
\text { during } 72 \mathrm{~h}\end{array}$ & $39.4 \pm 10$ & $1.34 \pm 0.1$ & \\
\hline Flax/Epoxy & \multirow{4}{*}{ curing } & \multirow{4}{*}{$\begin{array}{c}65^{\circ} \mathrm{C} \\
\text { during } 14 \mathrm{~h}\end{array}$} & $17.3 \pm 5.4$ & $1.56 \pm 0.09$ & \\
\hline Flax/Polyester & & & $15.2 \pm 2.3$ & $1.65 \pm 0.1$ & \\
\hline Glass/Epoxy & & & $25.7 \pm 2.1$ & $1.52 \pm 0.04$ & \multirow{2}{*}{ [11] } \\
\hline Glass/Polyester & & & $15.5 \pm 2.5$ & $1.5 \pm 0.14$ & \\
\hline
\end{tabular}




\begin{tabular}{|c|c|c|c|c|c|c|c|}
\hline Material & $\begin{array}{c}\text { Thermal } \\
\text { treatment }\end{array}$ & $\begin{array}{c}E_{m} \\
(\mathrm{MPa})\end{array}$ & $\begin{array}{c}\sigma_{\mathrm{m}} \\
(\mathrm{MPa})\end{array}$ & $\mathrm{V}_{\mathrm{m}}$ & $\begin{array}{c}\mathrm{G}_{\mathrm{m}} \\
(\mathrm{MPa})\end{array}$ & $\begin{array}{c}\mathrm{T}_{\mathrm{m}} \\
(\mathrm{MPa})\end{array}$ & $\begin{array}{l}\alpha\left(/^{\circ} \mathrm{C}\right) \\
(\mathrm{T}<\mathrm{Tg}) \\
\end{array}$ \\
\hline \multirow{4}{*}{ PLLA } & $93^{\circ} \mathrm{C} / \mathrm{min}$ & $\begin{array}{c}3029 \pm \\
410\end{array}$ & $56 \pm 1$ & $\begin{array}{r}0.162 \\
\pm 0.02\end{array}$ & $\begin{array}{c}1303 \pm \\
476\end{array}$ & $\begin{array}{c}33 \pm \\
0.6\end{array}$ & \multirow{4}{*}{$\begin{array}{c}(78 \pm \pm \\
\text { 2. }) * 10^{-6}\end{array}$} \\
\hline & $\begin{array}{c}15.5^{\circ} \mathrm{C} / \mathrm{mi} \\
\mathrm{n}\end{array}$ & $\begin{array}{c}3743 \pm \\
368\end{array}$ & $\begin{array}{c}60.9 \pm \\
3.2\end{array}$ & $\begin{array}{r}0.162 \\
\pm 0.03 \\
\end{array}$ & $\begin{array}{c}1609 \pm \\
144\end{array}$ & $\begin{array}{c}35.2 \pm \\
1.8\end{array}$ & \\
\hline & $1.5^{\circ} \mathrm{C} / \mathrm{min}$ & $\begin{array}{c}4003 \pm \\
410\end{array}$ & $\begin{array}{c}64.4 \pm \\
1 \\
\end{array}$ & $\begin{array}{r}0.148 \\
\pm 0.02 \\
\end{array}$ & $\begin{array}{c}1743 \pm \\
176\end{array}$ & $\begin{array}{c}37.8 \pm \\
3.3 \\
\end{array}$ & \\
\hline & Annealing & $\begin{array}{c}3394 \pm \\
149 \\
\end{array}$ & $\begin{array}{c}58.3 \pm \\
3 \\
\end{array}$ & $\begin{array}{r}0.163 \\
\pm 0.01 \\
\end{array}$ & $\begin{array}{c}1463 \pm \\
120\end{array}$ & $\begin{array}{c}33.7 \pm \\
1.7\end{array}$ & \\
\hline
\end{tabular}

Table 4. Thermal properties of PLLA

\begin{tabular}{|c|c|c|c|c|c|c|}
\hline Material & $\begin{array}{l}\text { Thermal } \\
\text { Treatment }\end{array}$ & $\begin{array}{l}\text { Crystallization } \\
\text { enthalpy }(\mathrm{J} / \mathrm{g})\end{array}$ & $\begin{array}{c}\text { Melting } \\
\text { enthalpy } \\
(\mathrm{J} / \mathrm{g})\end{array}$ & $\begin{array}{l}\text { Degree of } \\
\text { crystallinit } \\
y(\%)\end{array}$ & $\begin{array}{l}\text { Stress free } \\
\text { temperatur } \\
\text { e } T_{\text {free }}\left({ }^{\circ} \mathrm{C}\right)\end{array}$ & $\begin{array}{c}\Delta \mathrm{T} \\
\left(\mathrm{T}_{\text {free }}-\right. \\
\left.\mathrm{T}_{\text {test }}\right)\end{array}$ \\
\hline \multirow{4}{*}{ PLLA } & $\begin{array}{c}\text { Air } \\
\text { cooling }\end{array}$ & 10.9 & 11.3 & I & 58 & 35 \\
\hline & $10^{\circ} \mathrm{C} / \mathrm{min}$ & 7 & 18 & 11.7 & 102 & 79 \\
\hline & $1^{\circ} \mathrm{C} / \mathrm{min}$ & 1 & 41 & 43 & 117 & 94 \\
\hline & annealing & 9.4 & 10.5 & 0.01 & 58 & 35 \\
\hline
\end{tabular}

Table. 5. Tensile and shear properties of PLLA matrix as a function of thermal treatment 


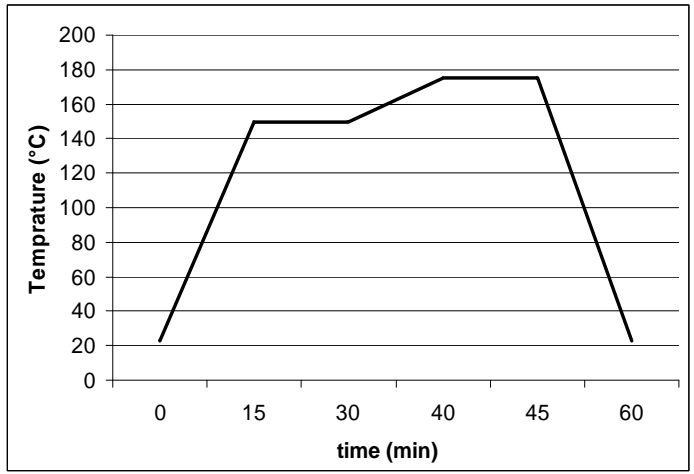

Fig. 1. Example of temperature programme for microdroplet manufacture with cooling rate of $10^{\circ} \mathrm{C} / \mathrm{min}$

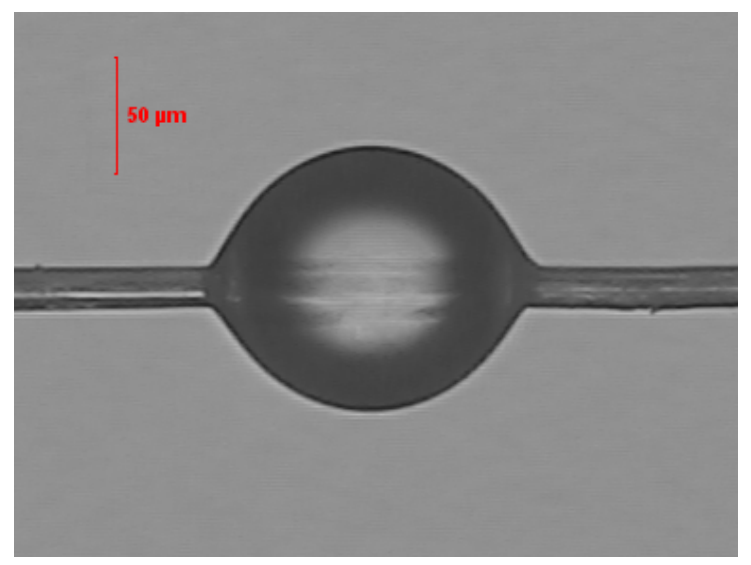

Fig. 2. Example of symmetrical PLLA microdroplet on flax fibre

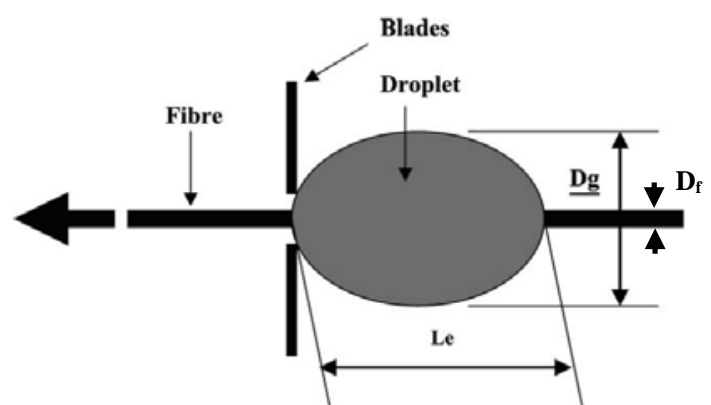

Fig.3 Schematic diagram of microbond test [6] 


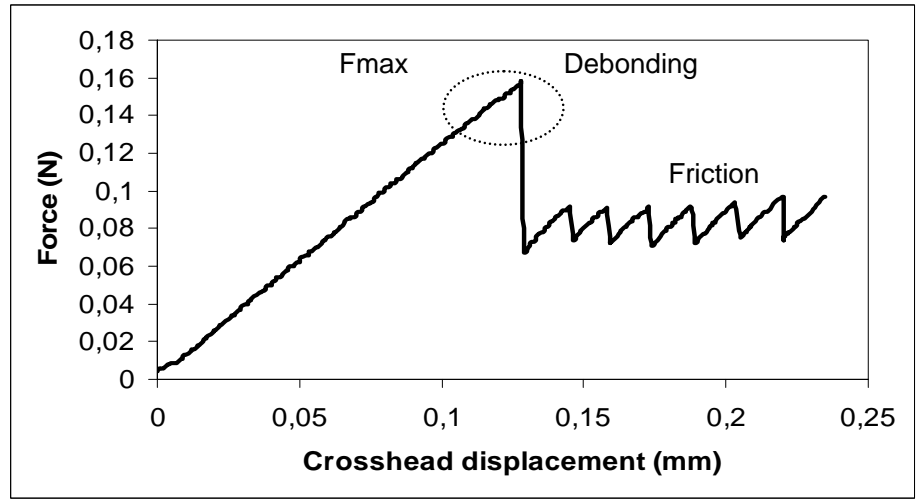

Fig.4 Typical Force versus Crosshead displacement plot

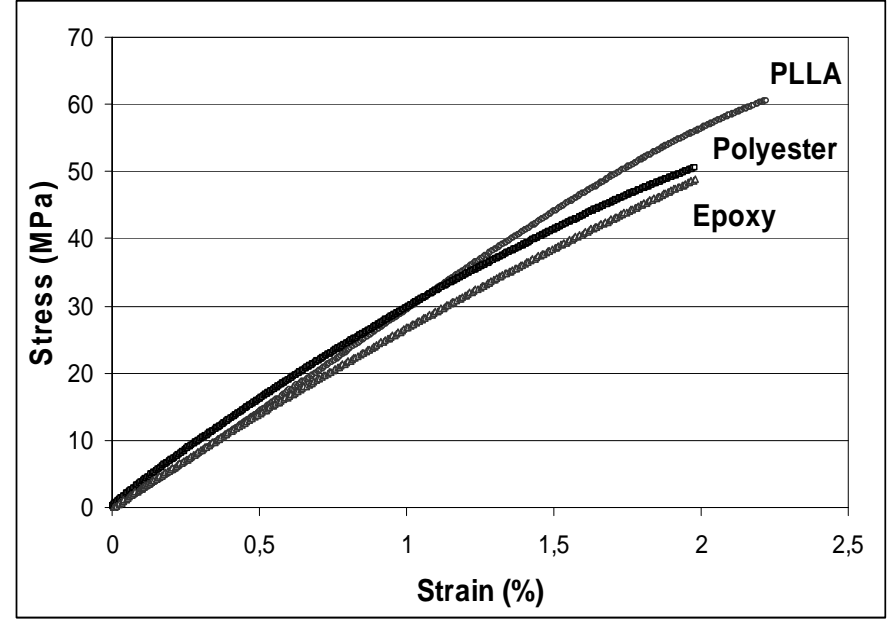

Fig. 5 Tensile behaviour of PLLA (air cooled) compared to Polyester and Epoxy resins (cured at $65^{\circ} \mathrm{C}$ for $14 \mathrm{~h}$ )
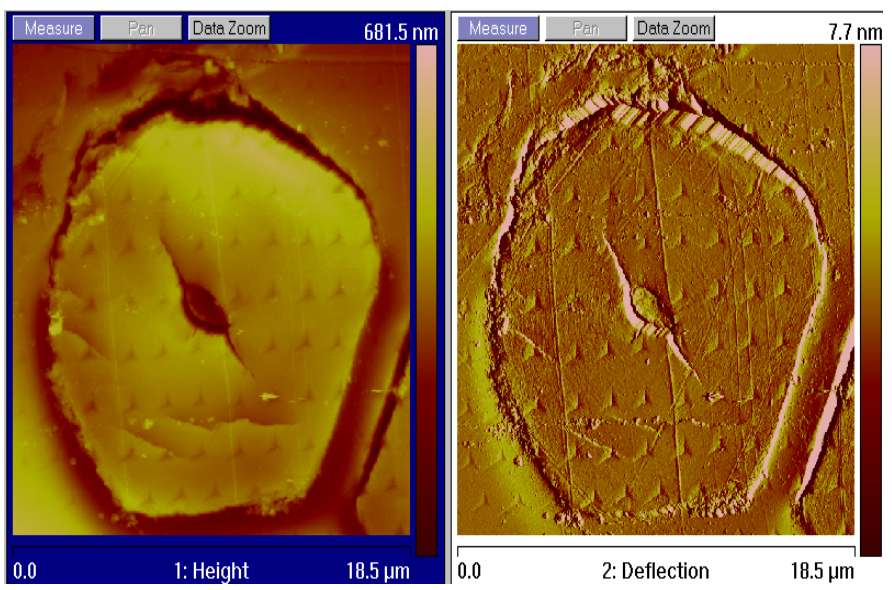

Fig.6 Atomic Force Microscopy (AFM) images of flax fibre section (after nano-indentation) 

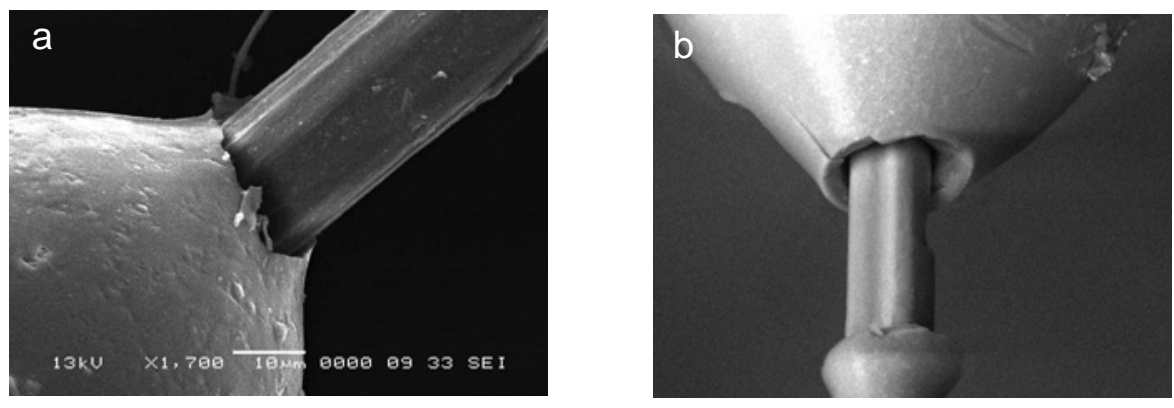

Fig. 7 a : PLLA microdroplet on flax fibre; b : Epoxy droplet cured at $65^{\circ} \mathrm{C}$
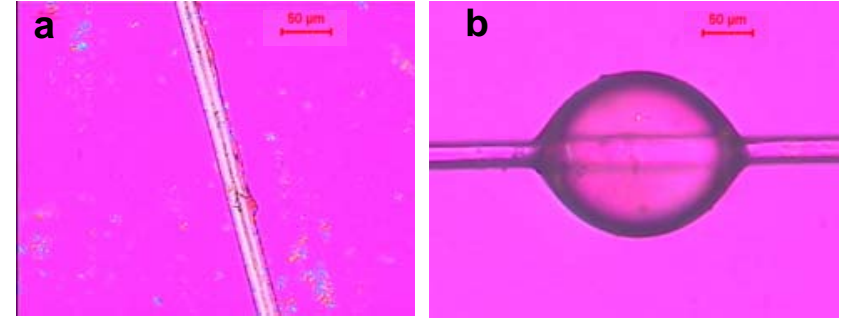

Fig. 8 : Air cooling ; a : PLLA/flax/PLLA stack; b: microdroplet
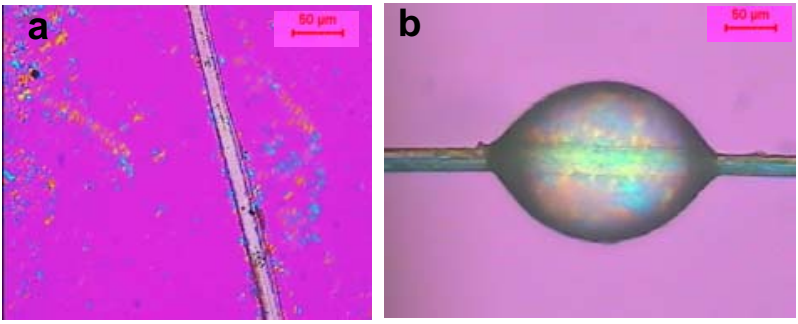

Fig. 9 : $10^{\circ} \mathrm{C} / \mathrm{min} ; \mathrm{a}:$ PLLA/flax/PLLA stack; $\mathrm{b}$ : microdroplet
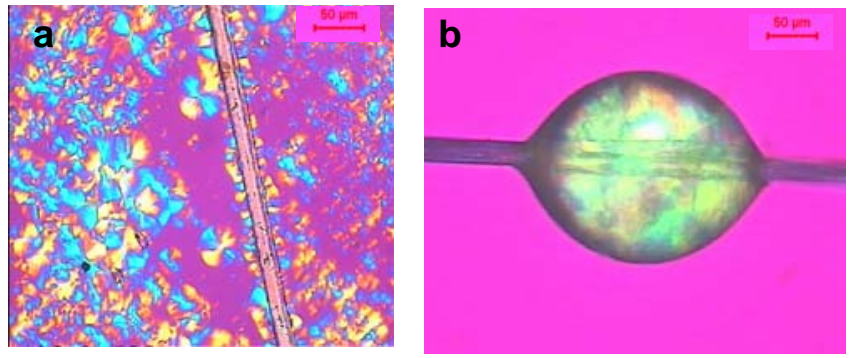

Fig. $10: 1^{\circ} \mathrm{C} / \mathrm{min}$; a : PLLA/flax/PLLA stack; b: microdroplet 